\title{
A REFORMA TRABALHISTA E A DISPUTA PELA REGULAÇÃO DO DIREITO DO TRABALHO NO BRASIL
}

\author{
LABOR REFORM AND DISPUTE FOR THE REGULATION OF LABOR LAW IN \\ BRAZIL
}

Eugenio Eduardo Pimentel Moreira ${ }^{1}$

RESUMO

Antônia de Abreu Sousa ${ }^{2}$

Este texto apresenta um ensaio teórico que tem como objetivo geral fomentar a discussão epistemológica, jurídica e sociológica acerca da Reforma Trabalhista no Brasil. Os objetivos específicos do estudo estão concentrados em: abordar a epistemologia do Direito do Trabalho, a partir da evolução histórica, dos paradigmas estruturais e de sua relação com a sociedade e explicitar as bases da flexibilização do trabalho trazidas pela Reforma Trabalhista. No campo metodológico adotou-se a pesquisa exploratória de abordagem qualitativa, valendo-se ainda da pesquisa bibliográfica e documental para o embasamento teórico e exploração do tema. Para a discussão e análise dos dados, foi adotado o método da análise de conteúdo (BARDIN, 2011). O referencial teórico se baseou em diferentes autores, que discutem Trabalho, Direito do Trabalho e a Reforma Trabalhista no Brasil, tais como: Antunes (2004, 2018); Belluzzo (2012); Cassar (2018); Delgado (2004); Martins e Rodrigues, 1999); Marx (2004); Ianni (1996), dentre outros. Os resultados sugerem que a reforma trabalhista contribui para uma maior degradação do trabalho no Brasil, na medida em que submete o trabalhador a mais insegurança e amplia a liberdade do empregador em determinar as condições de contratação, o uso da mão de obra e a remuneração do trabalho e, com efeito, impondo uma precarização estrutural e o desmonte da legislação social protetora do trabalho.

Palavras-chave: Trabalho. Direito do Trabalho. Reforma Trabalhista.

\begin{abstract}
This text presents a theoretical essay that has as general objective to foment the epistemological, juridical and sociological discussion about the Labor Reform in Brazil. The specific objectives of the study are focused on: addressing the epistemology of Labor Law, based on historical evolution, structural paradigms and their relationship with society and explain the basis of the flexibility of work brought about by the Labor Reform. In the methodological field, the exploratory research of qualitative approach was adopted, using bibliographical and documentary research for the theoretical basis. For the discussion and analysis of the data, the content analysis method was adopted (BARDIN, 2011). The theoretical framework was based on different authors, who discuss Labor, Labor Law and Labor Reform in Brazil, such as: Antunes (2004, 2018); Belluzzo (2012); Cassar (2018); Delgado (2004); Martins and

\footnotetext{
${ }^{1}$ Graduado em Pedagogia com habilitação em Administração Escolar pela Universidade Estadual do Ceará (UECE) e em Direito, pela Universidade de Fortaleza (UNIFOR). Especialista em Gestão de Recursos Humanos pela UECE e em Direito Processual, pela Faculdade 7 de Setembro (FA7). Mestre e Doutor em Educação Brasileira, pela Universidade Federal do Ceará (UFC). Professor do Instituto Federal de Educação, Ciência e Tecnologia do Ceará (IFCE). E-mail: eugenio.moreira@ifce.edu.br.

${ }^{2}$ Doutora em Educação com ênfase em Financiamento da Educação, pela Universidade Federal do Ceará. Professora no Instituto Federal de Educação, Ciência e Tecnologia do Ceará - IFCE. Coordena o Núcleo de Pesquisa em Educação Profissional (NUPEP) e participa do Laboratório de Estudos sobre o Trabalho e Qualificação Profissional (LABOR). Professora colaboradora do Programa de Pós-Graduação em Educação Brasileira da Universidade Federal do Ceará (UFC), do Programa de pós-graduação em Artes (IFCE) e do Programa em rede nacional de Educação Profissional e Tecnológica (PROFEPT).

Revista Labor Fortaleza/CE, jul/dez 2018 nº 20, Vol. 01, pp. 54-77 ISSN 1983-5000
} 
Rodrigues, 1999); Marx (2004); Ianni (1996), among others. The results suggest that the labor reform contributes to a greater degradation of work in Brazil, since it subjects the worker to greater insecurity and increases the freedom of the employer to determine the conditions of hiring, the use of labor and the remuneration of the worker and, in effect, imposing a structural precariousness and the dismantling of social legislation that protects labor.

Keywords: Work. Labor Law. Labor Reform.

\section{INTRODUÇÃO}

No Brasil, o debate acerca da imposição de uma reforma trabalhista não é novo. Desde o governo de Fernando Collor já havia a proposição de tornar menos rígida a legislação, cujas justificativas políticas perpassavam pela a indispensabilidade de flexibilizar as relações de trabalho para combater a crise do desemprego e, com efeito encolher a informalidade (Martins e Rodrigues, 1999).

O projeto desse governo, em linhas gerais, objetivava estancar o processo inflacionário por meio de recessão violenta, do arrocho salarial, do enxugamento da liquidez, da redução do déficit público e da privatização do Estado (Antunes, 2004). Mas esses planos de governo fracassaram e empobreceram ainda mais o país e Collor passa a contar com a desconfiança do empresariado e com uma expressiva insatisfação da população, o que acabou por inviabilizar as tentativas de reformulações da legislação trabalhista.

O Fernando Henrique Cardoso - recém-eleito com uma significativa aceitação da população e com um enorme apoio dos meios de comunicação - após enfrentar uma greve dos petroleiros que abalou o país por 31 dias, entre maio e junho de 1995 - conseguiu reunir os meios necessários para implementar um projeto neoliberal de governo, que também incluiu em sua agenda governamental modificações no Direito do Trabalho.

Apoiando-se numa proposta de "modernização" e diante de um cenário de desemprego acentuado, conseguiu sancionar uma série de medidas pontuais de flexibilização que atingiram os sujeitos da relação de emprego. As principais inovações jurídicas implementadas diziam respeito ao contrato por prazo determinado, contrato parcial, ampliação do período para utilização do contrato temporário, flexibilização da jornada por meio do banco de horas, liberalização do trabalho aos domingos, fim dos mecanismos de indexação do salário mínimo e a introdução de mecanismos privados de solução de conflitos (mediação, arbitragem e Comissão de Conciliação Prévia).

Essa agenda política do Fernando Henrique se consolidou, inclusive através de negociação com grande parte do movimento sindical. Apesar disso, houve três importantes matérias apresentadas que não foram viabilizadas politicamente: (1) a liberalização da 
terceirização; (2) a prevalência do negociado sobre o legislado; e, (3) a reforma da organização sindical.

Em 2002, adentrávamos no governo de Luiz Inácio Lula da Silva que, após sua quarta disputa eleitoral, foi eleito Presidente da República. E agora, com o Partido dos Trabalhadores (PT) à frente do governo, quais as perspectivas para os trabalhadores?

Para Antunes,

[...]após dois mandatos consecutivos de Fernando Henrique Cardoso, o Brasil havia se constituído em um país bastante diverso das décadas anteriores. A eleição de Lula ocorreu quando o transformismo já havia sido assimilado e interiorizado pela direção política do PT, [...], ainda que em movimento lento que acabou por convertê-lo em uma espécie de Partido da Ordem, cada vez mais moderado e institucionalizado em seus métodos, práticas e ações. (ANTUNES, 2018, p. 275-276).

Em 2002, as circunstâncias eram outras e o neoliberalismo, que se desenvolveu nos anos 1990, havia transformado em boa medida o país, e “o PT já não era mais um partido centralmente voltado para os interesses da classe trabalhadora" (ANTUNES, 2018, p. 276). Para ter uma chance efetiva de ganhar as eleições, Lula deveria se mostrar adaptado à nova ordem do mundo financeiro globalizado e, para demonstrar isso, o PT publicou a conhecida "Carta aos brasileiros", onde procurou tranquilizar o mercado financeiro e, especialmente, ao Fundo Monetário Internacional (Antunes, 2018).

Entretanto, dentro do redesenho de uma nova política, o PT tinha o desafio de representar os anseios populares, dos movimentos sociais e de sua militância política e, ao mesmo tempo, atender à prescrição imposta pelo capital financeiro. Então, o governo Lula instaurou de forma exitosa uma política policlassista conciliadora, preservando os interesses da classe burguesa ao mesmo tempo que promoveu programas sociais voltados para os mais pobres (ANTUNES, 2018).

Foi nesse contexto que houve a iniciativa do governo Lula de realizar uma reforma sindical e trabalhista, entre 2004 e 2005, por meio da constituição do Fórum Nacional do Trabalho (FNT), com participação tripartite, que chegou a encaminhar uma proposta ao Congresso Nacional, mas que não logrou sucesso, pois seu trâmite foi obstado pela forte resistência de diversos setores sindicais e pelas interferências políticas decorrentes das denúncias do esquema de corrupção denominado de "mensalão".

Todavia, posteriormente, em 2008, parte das medidas pensadas naquele Fórum acabou sendo contemplada pela Lei $\mathrm{n}^{\circ} 11.648$, de 2008, que legalizou as centrais sindicais brasileiras, estabelecendo os requisitos para que fossem reconhecidas oficialmente. A lei 
também alterou a CLT, estabelecendo novos critérios de distribuição do imposto sindical de forma a contemplar as centrais (ANTUNES, 2018).

Em suma, no governo Lula, as questões relacionadas aos direitos trabalhistas individuais não chegaram a ser implementadas, fazendo com que também não houvesse uma reforma trabalhista e sindical geral, mas apenas mudanças pontuais.

Em 1 de janeiro de 2011, Dilma Rousseff assume a Presidência da República. Seu governo foi conturbado pela crise econômica que criava um clima de incertezas e deixava insatisfeitos os setores produtivos que passaram a intensificar a pressão pela alteração das regras formais das relações de trabalho. Essa recessão econômica foi acentuada pelo desemprego e por um rebaixamento de salários, cujo descontentamento permeou todas as classes sociais, levando à eclosão das manifestações populares de $2013^{3}$. Aqui, o governo do PT mostra sinais de esgotamento.

Diante da crise conjuntural e política, a partir de 2014, a agenda de diminuição da proteção social aos trabalhadores ganhou ainda mais destaque. A presidente Dilma Rousseff, depois de reeleita, passou a apresentar uma política econômica mais ortodoxa e medidas de desconstrução de direitos, como, por exemplo, as medidas provisórias que criaram maiores restrições para os trabalhadores terem acesso ao seguro-desemprego e ao abono salarial ${ }^{4}$, medidas adotadas já dentro de uma política econômica de ajuste fiscal, que afetaram negativamente a sua base de sustentação na sociedade (KREIN, 2018).

Em 2015, as crises econômica e política se aprofundaram e a agenda da retirada de direitos ganhou ainda mais expressão. Dentre as iniciativas se destacaram a votação do Projeto de Lei $n^{\circ} 4330 / 2004^{5}$ na Câmara dos Deputados, que regulamentava a terceirização.

Valendo-se do avanço das mobilizações sociais pelo impeachment e da crise institucional de confronto entre os Poderes Executivo e Legislativo que se intensificava, foi apresentado à sociedade pelo Partido do Movimento Democrático Brasileiro (PMDB), ainda em 2015, um programa ultraliberal intitulado "Uma ponte para o Futuro" que tinha como finalidade ganhar apoio da elite econômica para Michel Temer, e que já previa as privatizações, a redução do gasto social, a reforma da previdência e a reforma trabalhista.

\footnotetext{
${ }^{3}$ A partir de uma passeata em São Paulo, em 6 de junho de 2013, com aproximadamente 2 mil pessoas, contra o aumento das tarifas no transporte público, passaram a ocorrer uma série de manifestações populares que atingiram seu ponto culminante em 17 de junho, com mais de 70 mil participantes em São Paulo e dezenas de milhares no Rio de Janeiro, em Porto Alegre, em Belo Horizonte e em diversas outras capitais do país, que demonstravam um forte descontentamento da população com o governo Dilma.

${ }^{4}$ Media Provisória convertida posteriormente na Lei ${ }^{\circ} 13.134 / 2015$.

${ }^{5}$ Projeto que promovia a liberalização total da terceirização e que chegou a ser aprovado na Câmara dos Deputados e a entrar em tramitação no Senado Federal como PLC 30/2015, onde ficou engavetado.
}

Revista Labor Fortaleza/CE, jul/dez 2018 n 20, Vol. 01, pp. 54-77 ISSN 1983-5000 
A partir de 31 de agosto de 2016, com o impeachment de Dilma, iniciou-se o governo de Michel Temer que vinha para seguir à risca a pauta que lhe foi imposta pelos grupos políticos e econômicos dominantes que lhe levaram ao comando da Presidência da República.

A proposta dos diversos setores empresariais para a reforma do Direito do Trabalho era clara: flexibilização das relações trabalhistas e começava, na opinião de muitos pesquisadores e juristas, a se implantar não uma simples reforma, mas um desconstrução de direitos, pois seriam modificados 201 dispositivos da Consolidação das Leis do Trabalho (CLT), que mudariam elementos centrais da relação de emprego e das instituições responsáveis pela efetivação das normas, "resultando numa desconstrução sem precedentes na história recente do trabalho no Brasil" (ANTUNES, 2018, p.15).

Além da Reforma Trabalhista, o governo federal e o Congresso brasileiro deram um duro golpe contra os mais pobres ao aprovarem o desmonte dos direitos sociais conquistados pelo povo brasileiro e, em 2017, entrou em curso a implementação de um conjunto de medidas que se traduzem no congelamento do gasto público por vinte anos, nas privatizações e nas concessões à iniciativa privada, na reforma do ensino médio, na política econômica ortodoxa e na tentativa da Reforma da Previdência (KREIN, 2018).

O governo adotou a estratégia de priorizar a Reforma Trabalhista em relação à Previdenciária (que continua em tramitação), pois a primeira, por ser uma iniciativa legislativa infraconstitucional, não precisava de quórum qualificado no Congresso Nacional e sua tramitação seria muito mais célere, se constituindo em um estratagema para Temer ganhar apoio empresarial e do "mercado", em um cenário no qual o Presidente começava a sofrer um profundo desgaste por conta dos escândalos de corrupção que envolviam seu nome.

Foi na perspectiva de fomentar a discussão epistemológica, jurídica e sociológica acerca da Reforma Trabalhista no Brasil promovida pelo governo Temer, que se realizou o presente estudo, com os objetivos específicos de: abordar a epistemologia do Direito do Trabalho, a partir da evolução histórica, dos paradigmas estruturais e de sua relação com a sociedade e explicitar as bases da flexibilização do trabalho trazidas pela Reforma Trabalhista no Brasil.

No campo metodológico, adotou-se a pesquisa exploratória de abordagem qualitativa, valendo-se ainda da pesquisa bibliográfica e documental para o embasamento teórico e exploração do tema. Para a discussão e análise dos dados, foi adotado o método da análise de conteúdo (BARDIN, 2011). Por meio da Análise de Conteúdo, buscou-se identificar os sentidos do que emerge dos dados. A investigação se deu com foco nos dois documentos oficiais 
que regulamentam a Reforma Trabalhista: as Leis 13.467/2017 e 13.429/2017. A unidades de análise definida foi a regulação das relações de trabalho, tendo como categorias o Direito do Trabalho e a flexibilização das relações de trabalho.

Obviamente, já há algumas análises acerca da Reforma Trabalhista, mas, no atual momento histórico às voltas das eleições presidenciais de 2018 que recolocam a matéria em pauta face os enormes desafios na geração de trabalho, emprego e renda que o Brasil enfrenta, o presente estudo se justifica e tenciona aprofundar a compreensão, sobretudo, do retrocesso que se deu com as novas regras de desproteção social e precarização das relações de trabalho que essa Reforma impôs de forma arbitrária aos trabalhadores brasileiros.

Esse texto está dividido em quatro partes bem fundamentadas. A primeira parte, que é introdutória, traz resumidamente um balanço das proposições políticas de flexibilizações do Direito do Trabalho, que se deram entre o governo Collor até as medidas impostas por Temer, que culminaram com a Reforma Trabalhista. A segunda trata das questões epistemológicas do Direito do Trabalho, incluindo um retrospecto da evolução histórica e uma análise dos paradigmas estruturais e de sua relação com a sociedade. Na terceira parte, serão analisados os elementos principais da reforma empreendida pela Lei $\mathrm{n}^{\circ} 13.467 / 2017$, dando ênfase às novas modalidades de contrato de trabalho incluídas no ordenamento jurídico pátrio, e pela Lei $n^{\circ} 13.429 / 2017$, que liberaliza a terceirização nas atividades permanentes das empresas, revelando as bases da flexibilização do trabalho e da diminuição da proteção social. A quarta refere-se às considerações finais que expõe os entendimentos revelados ao longo das análises, dando conta dos achados deste estudo.

Nessa exposição, não se intenciona esgotar quaisquer discussões acerca da Reforma Trabalhista, mas sim contribuir com aqueles que almejam entender, holisticamente, os reais significados da nova legislação no mundo das relações de trabalho.

\section{A QUESTÃo EPISTEMOLÓGiCA E A DISPUTA PELA REGULAÇÃo DO DIREITO DO TRABALHO}

A discussão sobre a questão epistemológica do Direito do Trabalho nos parece um ponto de partida fértil para chegarmos a ressignificação desse ramo do direito, diante das atuais demandas sociais postas pela Reforma Trabalhista no Brasil. Mas, para se justificar e discutir a epistemologia do Direito do Trabalho, faz-se necessário, antes, discorrer abreviadamente sobre o trabalho humano. 
Iniciemos do ponto de vista histórico e etimológico da palavra trabalho que, no passado, denotava algo desagradável: castigo, sofrimento, tortura, cuja origem é o termo em latim tripalium, uma espécie de instrumento de tortura ou canga que pesava sobre os animais. Com o passar dos tempos, o trabalho adquire um sentido positivo. Constata-se essa mudança de sentido na obra do filósofo inglês John Locke (1632-1704), não por acaso, teórico do liberalismo burguês.

Para justificar a propriedade pessoal de algo que no início dos tempos teria sido comum a todos, Locke diz que

[...] cada um guarda a propriedade de sua própria pessoa; sobre esta ninguém tem qualquer direito exceto ela. Podemos dizer que o trabalho de seu corpo e a obra produzida por suas mãos são propriedade sua. Sempre que ele tira um objeto do estado em que a natureza o colocou e deixou, mistura nisso o seu trabalho e a isso acrescenta algo que lhe pertence, por isso o tornando sua propriedade. Ao remover este objeto do estado comum em que a natureza o colocou, através do seu trabalho adiciona-lhe algo que excluiu o direito comum dos outros homens. Sendo este trabalho uma propriedade inquestionável do trabalhador, nenhum homem, exceto ele, pode ter o direito ao que o trabalho lhe acrescentou. (LOCKE, 1994, p. 98.)

Outros pensadores, porém, criticaram as distorções desse processo de apropriação que se cumpriu em detrimento da maioria. No século XIX, Karl Marx denunciou as contradições da economia política burguesa, que reconhecia no trabalho a origem de todo o valor e de toda riqueza, mas de fato privilegiava a propriedade, e não o trabalhador.

Destacamos a importância que esse filósofo deu às relações de trabalho, como atividade por excelência pela qual cada ser humano se liberta da natureza e se humaniza porque, ao mesmo tempo que produz alguma coisa, também se autoproduz como pessoa. No entanto, foi também Marx quem desenvolveu a teoria da alienação no trabalho e, em particular, do estranhamento que - fazendo parte do complexo social da alienação - impede essa realização.

Nas palavras de Marx:

$\mathrm{O}$ trabalhador se torna tanto mais pobre quanto mais riqueza produz, quanto mais a sua produção aumenta em poder e extensão. $O$ trabalhador se torna uma mercadoria tão mais barata quanto mais mercadorias cria. Com a valorização do mundo das coisas (Sachenwelt) aumenta em proporção direta a desvalorização do mundo dos homens (Menschenwelt). O trabalho não produz somente mercadorias; ele produz a si mesmo e ao trabalhador como uma mercadoria, e isso na medida em que produz, de fato, mercadorias em geral.

Este fato nada mais exprime, senão: o objeto (Gegenstand) que o trabalho produz, o seu produto, se lhe defronta como um ser estranho, como um poder independente do produtor. O produto do trabalho é o trabalho que se fixou num objeto, fez-se coisa (sachlich), é a objetivação (Vergegenstandlichung) do trabalho. A efetivação (Verwirklichung) do trabalho é a sua objetivação. Esta efetivação do trabalho aparece ao estado nacional-econômico como desefetivação ( Entwirklichung) do trabalhador, a objetivação como perda do objeto, a apropriação como estranhamento (Entfremdung), como alienação ( Entausserung) (MARX, 2004, p.80). 
O estranhamento, portanto, se efetiva pela dimensão da negatividade, sentimento de perda e desefetivação, que caracteriza o trabalho assalariado no capitalismo, uma vez que o produto gerado pelo trabalho não pertence ao seu criador (Antunes, 2018). Também, a alienação do trabalhador surge, ao mesmo tempo, como alienação da atividade produtiva quando esta deixa de ser uma manifestação essencial do homem, para ser um "trabalho forçado", não voluntário, mas determinado pela necessidade externa, de sobrevivência.

Essa dedução de Marx faz despontar um outro momento em que o trabalhador aliena-se também do gênero humano, o que leva a uma quarta dimensão do complexo social do estranhamento: a alienação do homem pelo homem, ou seja, nas palavras de Antunes, "o ser se estranha em relação ao próprio ser, ele se separa de seu ser genérico.” (ANTUNES, 2018, p.98).

Nessas especificidades, concluímos que o trabalho alienado é condição de desumanização, pois o produto passa a valer mais do que o próprio trabalhador, que perde o controle desse produto e, por conseguinte, de si mesmo, comprometendo a possibilidade de atuar no mundo de modo autônomo e crítico.

Ao examinarmos, porém, as mudanças do trabalho na sociedade pós-industrial, talvez devêssemos nos perguntar se essas circunstâncias, seja na indústria, seja no setor de serviços, não teriam modificado de modo positivo a relação do trabalhador com seu ofício e com o dono do capital, para superar, ou pelo menos minimizar, a alienação?

No mundo do trabalho contemporâneo, embora persista a esperança em um trabalho não-alienante, que permita a autocriação humana, que supere a dimensão de sofrimento, o que se percebe é muito diverso desse desenho idealizado. Parafraseando Antunes (2018), o mundo do século XXI, mais do que nunca, mantém bilhões de homens e mulheres dependendo de forma quase que exclusiva do trabalho para sobreviver e encontram, cada vez mais, situações instáveis, vivenciando a corrosão de seus direitos sociais, de suas conquistas históricas e o exaurimento dos níveis de remuneração, em razão de uma lógica do mercado que lhes impõe novas modalidades de trabalho informal, intermitente, precarizado e flexível.

Assim, sem dúvida, os problemas na sociedade capitalista continuam existindo, pois apesar das riquezas produzidas, grande parte das pessoas que vivem do trabalho ainda não tem acesso aos seus bens fundamentais e precisam, por isso mesmo, de normas protetivas que lhes assegurem melhoras nas condições de trabalho. Nesse sentido, ao tratar do trabalho como atividade humana produtiva feita em favor de terceiros, é que é substancial desvelar o Direito do Trabalho. 


\section{TRÊS CORRENTES PRONUNCIAM-SE ACERCA DESSE RAMO DO DIREITO}

A primeira delas é a corrente subjetiva, que prioriza os sujeitos da relação de emprego: empregado e empregador. Sob essa ótica, destaca-se a fragilidade da condição econômica do empregado na relação jurídica. A segunda tendência é a objetiva que realça o conteúdo do Direito do Trabalho, isto é, a lei e não seus destinatários.

Ambas as correntes recebem críticas pois são insuficientes para entender Direito do Trabalho em sua plenitude. Na verdade, não há como separar uma corrente da outra, por isso a corrente majoritária é a chamada mista, que engloba as duas categorias acima, valorando tanto os sujeitos da relação de trabalho quanto o conteúdo do Direito do Trabalho. Isso porque o Direito do Trabalho supera a visão individualista e coletiva e perpassa pela visão econômica, política e social. Também não pode ser visto apenas como aquele que cuida da aplicação das regras trabalhistas. O Direito do Trabalho é muito mais amplo, pois possui implicação coletiva, social, com institutos nacionais e internacionais que visam à melhoria da condição social e proteção dos sujeitos da relação de trabalho. Outrossim, relaciona-se com questões econômicas e de globalização da economia, de mercado de trabalho, sociais e políticas.

Na visão de Cassar, o Direito do Trabalho

[...] é um sistema jurídico permeado por institutos, valores, regras e princípios dirigidos aos trabalhadores subordinados e assemelhados, aos empregadores, empresas coligadas, tomadores de serviço, para tutela do contrato mínimo de trabalho, das obrigações decorrentes das relações de trabalho, das medidas que visam à proteção da sociedade trabalhadora, sempre norteadas pelos princípios constitucionais, principalmente o da dignidade da pessoa humana. Também é recheado de normas destinadas aos sindicatos e associações representativas; à atenuação e forma de solução dos conflitos individuais, coletivos e difusos, existentes entre capital e trabalho; à estabilização da economia social e à melhoria da condição social de todos os relacionados. (CASSAR, 2018, p.5)

A principal característica do Direito do Trabalho é a proteção do trabalhador, seja por meio da regulamentação legal das condições mínimas da relação de emprego, seja por meio de medidas sociais adotadas e implantadas pelo governo e sociedade. Também, sob o aspecto coletivo do trabalho, traz como característica a busca pela solução e pacificação dos conflitos coletivos de trabalho, bem como nas formas de representação pelos sindicatos. Tais características conotam o caráter socializante da legislação trabalhista, realçando suas funções tutelar, econômica, pacificadora, política e social, que justificaram seu nascimento no século XIX e sua permanência nos ordenamentos jurídicos nacional e internacional. 
A par disso, vale ressaltar que o Direito do Trabalho nasce ${ }^{6}$ como reação da classe trabalhadora ao cenário que se apresentou com a Revolução Industrial, com a crescente e incontrolável exploração desumana do trabalho (CASSAR, 2018). Foi a partir daí que surgiram as legislações e constituições em proteger o trabalhador, considerado hipossuficiente na relação de trabalho.

Um dos primeiros defensores de normas regulamentadoras das relações de trabalho foi o industrial Robert Owen que, ao assumir a fábrica de tecidos em New Lamark, na Escócia, empreendeu profundas mudanças para a época, como a supressão dos castigos e prêmios; não admissão de menor de 10 anos; jornada de dez horas e meia de trabalho; medidas de higiene no trabalho; caixa de previdência para velhice e assistência médica (CASSAR, 2018). Talvez por isso, mais tarde, Robert Owen passa a ser considerado "o pai do Direito do Trabalho".

Segundo Cassar (2018), a partir das medidas de Robert Owen, outras medidas protetivas nas relações de trabalho passaram a ser pontualmente tomadas em outros países. Todavia, a legislação trabalhista só passa a ganhar status constitucional em 1917 com a Constituição do México. Esta foi a primeira Constituição mundial a proteger direitos de trabalhadores. Depois dela, tivemos a Constituição de Weimar (1919) ${ }^{7}$. O ano de 1919 foi marcado ainda pela criação da Organização Internacional do Trabalho (OIT), através do Tratado de Versailles.

No Brasil, em 1824, a Constituição do Império (art. 179, XXV), inspirada nos princípios da Revolução Francesa, assegurou ampla liberdade para o trabalho extinguiu as Corporações de Ofício.

Em 1850, tivemos o primeiro Código Comercial que foi o primeiro a trazer regras de Processo, Direito Civil e Direito do Trabalho. Ao tratar das relações de comércio, fazia menção ao armador e seus tripulantes, tratando também da possibilidade do aviso prévio, da indenização pela rescisão injusta do contrato a termo, da justa causa e da garantia de salário em caso de acidente de trabalho (CASSAR, 2018).

Em 1891, a Constituição assegura o livre exercício de qualquer profissão (art. 72, §24) e garante a liberdade de associação (art. 72, § $8^{\circ}$ ).

Dando um salto temporal para 1930, destaca-se a criação por Getúlio Vargas do Ministério do Trabalho, Indústria e Comércio, através do Decreto nº 19.443/30. “ A partir de então, houve uma farta legislação, através de decretos legislativos, tanto sobre previdência

\footnotetext{
${ }^{6}$ O Direito do Trabalho nasce com duas ramificações: Direito Individual do Trabalho e Direito Coletivo. Este último, com a preocupação abstrata e geral de proteção de interesses de categorias e/ou de empresários.

${ }^{7}$ A Constituição do Império Alemão que declarou a Alemanha como uma república democrática parlamentar.

Revista Labor Fortaleza/CE, jul/dez 2018 n 20, Vol. 01, pp. 54-77 ISSN 1983-5000
} 
social quanto a respeito das relações de trabalho (individuais e coletivas) até a promulgação da Carta de 1934." (CASSAR, 2018, p.17).

A Constituição Federal de 1934, segundo Cassar (2018), elaborada sob forte influência da Constituição de Weimar (social-democrata) e da Constituição americana (liberalindividualista), foi a primeira a elevar os direitos trabalhistas ao status constitucional dispostos nos arts. 120 a 121, tais como salário mínimo, jornada de oito horas, férias, repouso semanal (não era remunerado), pluralidade sindical, indenização por despedida imotivada, criação da Justiça do Trabalho, ainda não integrante ao Poder Judiciário.

Em 1937, houve o golpe e Getúlio Vargas e o Brasil entra em um regime ditatorial. Com apoio das Forças Armadas nova Constituição foi outorgada, mas acabou por manter os direitos trabalhistas conquistados na constituição anterior e ainda estabeleceu algumas regras ao Direito Coletivo do Trabalho: reconhecimento dos sindicatos; a imposição da contribuição sindical; unicidade sindical; e, previsão para contrato coletivo de trabalho. (CASSAR, 2018).

Ao meio do regime autoritário, em 1943, Getúlio Vargas cria a Consolidação das Leis do Trabalho (CLT) que, ao sistematizar e consolidar as diversas leis em um único texto, integrou os trabalhadores no círculo dos direitos mínimos e fundamentais. Em 1945, Getúlio é deposto.

A Constituição Federal de 1946 foi considerada democrática e dispôs sobre a participação de empregados nos lucros da empresa, o repouso semanal remunerado, feriados, concedeu estabilidade decenal a todos os trabalhadores, foi reconhecido o direito de greve, houve a inclusão da Justiça do Trabalho no Poder Judiciário, retirando este órgão da esfera do Executivo (CASSAR, 2018).

Em 31 de março de 1964, militares contrários ao governo de João Goulart destituíram o então presidente e assumiram o poder por meio de um golpe. O governo comandado pelas Forças Armadas durou 21 anos e implantou um regime ditatorial. A ditadura restringiu direitos, a participação popular e reprimiu com violência todos os movimentos de oposição.

Nessa conjuntura, as normas trabalhistas também sofreram restrições, tais como proibir o direito de greve para o serviço público e atividades essenciais. Entretanto, alguns direitos também foram criados, como, por exemplo, para trabalhadores domésticos (Lei $\mathrm{n}^{\circ}$ 5859/1972) e rurais (Lei $n^{\circ}$ 5889/1973).

Com a redemocratização do país, em 1988, foi promulgada a Constituição Cidadã que retoma o homem como figura principal a ser protegida, priorizando o coletivo, o social e a 
dignidade da pessoa. Em seu art. $7^{\circ}$, arrolou inúmeros direitos aos trabalhadores que visavam à melhoria de suas condições sociais.

Pode-se depreender desse breve retrospecto histórico que, houve, mundialmente, ao longo da história uma intensa evolução da legislação trabalhista, conferindo um caráter público às relações da esfera privada, em que o Estado toma para si a gestão de regras, a princípio, delegadas ao arbítrio dos particulares, buscando assim regular legalmente a relação jurídica travada entre empregados e empregadores, bem como visando compensar a parte economicamente mais fraca dessa relação com novos direitos. A esse respeito, Cassar (2018) entende que

\begin{abstract}
A necessidade de o Estado intervir na relação na relação contratual para proteger a parte hipossuficiente, até então regidas pelas leis de mercado, fio movida pela pressão da sociedade operária, pelas relações internacionais (Declaração Universal dos Direitos do Homem) e Tratado de Versailles, OIT) e pela ação da Igreja (Encíclica Rerum Novarum). (CASSAR, 2018, p. 21).
\end{abstract}

Nesse processo histórico, o capitalismo liberal e o mercado de trabalho passam por transformações, onde a globalização, neoliberalismo, privatizações, multinacionais, dentre outros elementos, interferem na estrutura e atribuições do Estado e de sua organização política, em suas relações internacionais e na ordem socioeconômica nacional e mundial. Nessas circunstâncias, as modificações que surgem no processo do trabalho e, com efeito, na economia geram consequências sentidas pelos trabalhadores: crise econômica, crescimento do desemprego, desigualdade social, nações desnacionalizadas, subordinadas aos ditames dos países mais ricos, etc.

Diante das crises, o capital reage questionando o excesso de proteção trabalhista e alguns defendem que tais direitos sejam reduzidos, flexibilizados ou desregulamentados, para possibilitar maior competitividade no mercado.

À vista disso, hoje, o Direito do Trabalho vive uma fase de transição onde se questiona a intervenção estatal em regras privadas. Alguns pretendem total desregulamentação, ou seja, a ausência total da intervenção do Estado nas relações de trabalho, deixando o contrato de trabalho livre e à mercê das regras de mercado.

Outros defendem apenas a flexibilização e/ou redução desses direitos, pois percebem que não se pode pretender o total afastamento do Estado, pois ainda temos em muitos países, como é o caso do Brasil, trabalho escravo ou em condições análogas, exploração do trabalho infantil e vários outros aspectos da legislação trabalhista desrespeitados. 
Assim, atualmente, um dos questionamentos que entra em discussão diz respeito aos dilemas do Direito do Trabalho sobre seu objeto e conteúdo. Estaria o Direito do Trabalho a caminho de perder o foco de sua finalidade, isto é, a mediação das relações trabalhistas, individuais e coletivas?

A resposta a essa pergunta parte exatamente do enfrentamento da questão epistemológica que é fundamental do ponto de vista da origem, da necessidade histórica e de sua importância para os problemas relacionados às relações trabalhistas complexas.

Observe-se que, historicamente, em face do desequilíbrio existente na relação travada entre empregado e empregador, a diretriz básica do Direito do Trabalho é equilibrar essa relação desigual e para tanto é necessário proteger do a parte economicamente mais fraca: o trabalhador (CASSAR, 2018). Com esse propósito, consagrou-se o princípio da proteção ao trabalhador, que é caracterizado pela intervenção do Estado para impor regras mínimas, inclusive de ordem constitucional, como as que estão preceituadas no art. $7^{\circ}$ da Constituição Federal de 1988.

No caso do Brasil, numa época em que as exigências da economia preconizam o triunfo do mercado e impõem a flexibilização das condições de trabalho por meio da Reforma Trabalhista, depreende-se que houve um retrocesso sim de direitos duramente conquistados. Entretanto, esse fato não revogou os princípios protetivos constitucionais e, por conseguinte, não retirará a imprescindibilidade do Direito do Trabalho, pois, a flexibilidade das leis não irá retirar o papel ativo do Estado de intervir na esfera privada para pacificação das relações de trabalho. Segundo Cassar (2018),

Flexibilizar pressupõe manutenção da intervenção estatal nas relações trabalhistas estabelecendo as condições mínimas de trabalho, sem as quais não se pode conceber a vida do trabalhador com dignidade (mínimo existencial), mas autorizando, em determinados casos, exceções ou regras menos rígidas, de forma que possibilite a manutenção da empresa e dos empregos. (CASSAR, 2018, p. 33).

E vale ressaltar que em países em desenvolvimento como o Brasil, muitas vezes, a utilização da força de trabalho ainda se realiza em condições absurdas, denominada por Ianni (1996) de superexploração que ele caracteriza da seguinte forma:

Superexploração: salários ínfimos, longas jornadas de trabalho "legitimadas" pelo instituto das horas extras, aceleração do ritmo de trabalho pela emulação do grupo de trabalho e pela manipulação da velocidade das máquinas e equipamentos produtivos, ausência ou escassez de proteção ao trabalhador em ambientes de trabalho, insegurança social. (IANNI, 1996, p. 174)

Nessas circunstâncias, sempre haverá resistência às manobras do capital, do neoliberalismo e à exploração dos trabalhadores e, desde que estejamos em um Estado 
Democrático de Direito, o acesso à Justiça possibilitará que o Direito do Trabalho continue a ser um impulsionador de transformações sociais.

Outrossim, é necessário ressalvar que, apesar da Reforma Trabalhista ter restringido o rol de direitos antes garantidos pela CLT e, ao mesmo tempo, ter limitado a atuação da Justiça do Trabalho, coibindo sua competência na interpretação de normas, edição de súmulas e enunciados de jurisprudência, o embate em torno dessa reforma ainda continua, pois como as modificações são infraconstitucionais, os dispositivos constitucionais não foram modificados, o que está causando controvérsias de interpretação jurídica, inclusive porque o Ministério Público do Trabalho tem defendido a inconstitucionalidade de vários pontos da reforma e que ela está em desacordo com convenções internacionais do trabalho subscrita pelo Brasil. Ou seja, haverá uma disputa jurídica sobre a aplicação das alterações trazidas pela reforma, o que pode provocar contradições nas jurisprudências.

Ademais, as negociações coletivas continuam tendo possibilidades de ditar regras para as relações de emprego, inclusive podendo validar ou contrapor-se a aspectos ou à totalidade do conteúdo da reforma.

Enfim, o propósito é indicar que a reforma traz inovações legais substantivas, mas o embate em torno da regulamentação do trabalho continua. Nesse sentido é que se pretende analisar na próxima seção as implicações que a reforma traz dentro das características das relações de trabalho no Brasil e da tendência recente de flexibilização do trabalho e de diminuição da proteção social, sobretudo, em razão da terceirização e das novas modalidades de contrato de trabalho.

\section{A FLEXIBILIZAÇÃO NA REGULAÇÃO DO TRABALHO E SEUS IMPACTOS NAS RELAÇÕES DE EMPREGO}

A reforma trabalhista representa uma transformação substantiva no modelo de regulação do trabalho no Brasil e seus efeitos tendem a ir além das relações de emprego, podendo causar impactos danosos sobre o mercado de trabalho, a economia, a vida pessoal, a familiar e a própria forma de organização da sociedade brasileira.

Isso pois, não obstante a legislação brasileira já dispor de dispositivos legais que flexibilizavam as formas de contratação e de rompimento do pacto laboral sem a necessidade de um justo motivo, a Reforma Trabalhista procurou ampliar a liberdade das empresas para manejar o trabalho de acordo com as suas necessidades, fundamentalmente buscando eliminar eventuais entraves ou obstáculos oriundos das instituições públicas. Assim, ela tem a finalidade 
de "legalizar" práticas de flexibilização e de redução de custos e ampliar ainda mais o cardápio de opções de manejo da força de trabalho e intensificar ainda mais a diminuição dos salários, a intensa precarização do trabalho, o que pode incrementar substancialmente o desemprego e o aumento da informalidade.

De forma sintética, pretende-se apresentar os principais os elementos da relação de emprego que reforma modifica e, na sistematização das principais mudanças, inicialmente, destacam-se as novas formas de contratação de mão de obra.

Em primeiro lugar sobressai a liberalização total da terceirização, ao permitir a sua utilização inclusive em atividade-fim e em qualquer setor de atividade. A terceirização é compreendida como um mecanismo jurídico que permite a um sujeito de direito tomar serviços no mercado de trabalho sem responder, diretamente, pela relação empregatícia estabelecida com o respectivo trabalhador. (DELGADO, 2004).

A terceirização não é uma estratégia de gestão recente. Nas últimas décadas, vinha sendo uma tendência nas atividades-meio na indústria, nos serviços, na agricultura e na Administração Pública. Agora, a diferença é que se amplia também para as atividades-fim.

Expandir as hipóteses de terceirização para as atividades principais (atividades-fim) de uma empresa sob argumento de que tal medida visa a modernização, a especialização das atividades produtivas, criação de novos empregos e reduz informalidades é apenas um discurso que dissimula o objetivo principal que é a redução de custos com mão de obra que se dá com a diminuição do valor salarial e de direitos dos terceirizados, pois se sabe que não será mais necessário respeitar o piso normativo dos empregados do tomador de serviços nem a isonomia de benefícios entre eles.

Cassar (2018, p. 501) afirma que "A lei não exige isonomia de tratamento entre trabalhadores terceirizados e os empregados da empresa tomadora de serviços, salvo em se tratando de trabalhador temporário, quanto à remuneração (art. 12, a, Lei no 6.019/74).”.

A jurista ainda destaca o fato da categoria sindical do empregado terceirizado relacionar-se à atividade desenvolvida por seu empregador. Ou seja, “[...] o trabalhador terceirizado pertencerá à categoria sindical relativa à atividade da empresa prestadora de serviço, da qual é empregado, e não àquela da empresa tomadora, que normalmente é mais favorável." (CASSAR, 2018, p. 501).

Assim,

“[...] a terceirização aumenta ainda mais a fragmentação, a heterogeneização e a divisão intraclasse trabalhadora, além da concorrência entre os que trabalham no mesmo espaço produtivo. Impõe, dessa forma, uma divisão entre os distintos sindicatos existentes em uma mesma empresa." (ANTUNES, 2018, p.150). 
Atualmente, até a Administração Pública que, em regra, deve prestar serviços públicos sem fins lucrativos, torna-se partícipe (diretamente ou indiretamente) do processo de valorização do capital e de criação ou realização do mais valor, impulsionando a terceirização.

Recentemente, o governo federal editou o Decreto $n^{\circ}$ 9.507, de 21/9/2018, que regulamenta a terceirização no serviço público federal, abrangendo administração direta, autarquias, fundações, empresas públicas e sociedade de economia mistas controladas pela União. Até então, só podiam ser objeto de terceirização, em órgão públicos, as atividades-meio como limpeza, segurança, transportes, informática, recepção, telecomunicações e manutenção de prédios e equipamentos. Mas, no novo decreto, não existe mais de forma expressa quais são os serviços que podem ser terceirizados. Nesse sentido, as novas regras permitem a ampliação da terceirização no serviço público e, consectariamente, favorece a iniciativa privada que atua nesse setor de serviços.

Outra modalidade de contrato de trabalho trazida pela Reforma Trabalhista foi o contrato intermitente ${ }^{8}$, que "é aquele que alterna períodos de atividade (trabalho) e inatividade (não trabalho), sendo que estes não são computados nem remunerados" (CASSAR, 2018, p. 511).

A maior característica do contrato intermitente não é apenas a alternância dos períodos de atividade com de inatividade, mas a imprevisibilidade do trabalho. Por isso, é também chamado de "contrato-zero". Isto significa que o trabalhador será admitido, com a carteira assinada, para não trabalhar, até que haja a necessidade do serviço por parte do empregador (CASSAR, 2018).

Para execução do serviço, basta que o empregador convoque o empregado intermitente, por qualquer meio eficaz, para apresentação de serviços, noticiando a jornada, que não poderá ser superior à legal, sempre com antecedência mínima de três dias corridos $\left(\S^{\circ}\right.$ do art. 452-A da CLT). Recebida a convocação, o empregado terá o prazo de vinte e quatro horas para responder, presumindo o silêncio como recusa, que o não descaracteriza a subordinação inerente ao vínculo de emprego.

De acordo com o $\S 6^{\circ}$ do art.452-A da CLT, ao final de cada período de prestação de serviço, o empregado receberá o pagamento imediato da remuneração, das férias proporcionais com acréscimo de um terço, do décimo terceiro proporcional, do repouso semanal remunerado e dos adicionais legais a que fizer jus.

\footnotetext{
${ }^{8} \mathrm{~A}$ Lei n ${ }^{\circ} 13.467 / 2017$ acrescentou à CLT os arts. 452-A e seguintes e alterou o art. 443 para criar o contrato intermitente. Revista Labor Fortaleza/CE, jul/dez 2018 n² 20, Vol. 01, pp. 54-77 ISSN 1983-5000
} 
Apesar das garantias mínimas, essa nova modalidade de contrato gera extrema insegurança ao trabalhador, que não tem nenhuma garantia da quantidade mínima de trabalho por mês ou de quantos meses irá trabalhar no ano. Também não tem o tempo de inatividade computado como tempo de serviço.

A instabilidade e a insegurança são traços constitutivos dessa modalidade de contrato. À vista disso, Cassar (2018)

\begin{abstract}
A criação de mais uma espécie de contrato de trabalho sob a denominação "contrato intermitente" visa, na verdade, autorizar a jornada móvel variada e o trabalho variável (bico), isto é, a imprevisibilidade da prestação de serviços, ferindo de morte os princípios da segurança jurídica, o da proteção ao trabalhador e o da continuidade da relação de emprego. A alteração da lei para permitir esta espécie de contrato atende principalmente aos interesses dos empresários, e não dos trabalhadores. (CASSAR, 2018, p. 515).
\end{abstract}

Outra espécie de contrato de trabalho trazida pela Lei n 13.467/2017 é teletrabalho, disciplinado no Capítulo II-A, na CLT. O art. 75-B da CLT passa a considerar como teletrabalho “a prestação de serviços preponderantemente fora das dependências do empregador, com a utilização de tecnologias de informação e de comunicação que, por sua natureza, não se constituam como trabalho externo".

Essa modalidade laborativa, que se utiliza de outros espaços fora da empresa para realizar as atividades, pode trazer vantagens, como economia de tempo em deslocamentos do empregado, permitindo uma melhor divisão entre trabalho produtivo e reprodutivo, dentre outros pontos positivos. Todavia, também apresenta aspectos negativos para o trabalhador. Antunes (2018) aponta que esse instituto pode incentivar o trabalho isolado, desprovido do convívio social e coletivo.

Além disso, abre possibilidades para eliminação dos direitos do trabalho como, por exemplo, o não pagamento pelo horário extraordinário de trabalho. Isso, porque, de forma perversa, o legislador incluiu no inciso III do art. 62 da CLT o teletrabalhador, de modo a retirar a proteção à jornada de trabalho, desconsiderando o grande avanço tecnológico que permite atualmente aos empregadores controlar a localização exata do trabalhador, as atividades que estão sendo desempenhadas e os horários de início e fim.

Mais uma opção para os empregadores poderem ajustar a quantidade e os custos do trabalho às suas necessidades diz respeito à possibilidade da contratação do autônomo de forma permanente (art. 442-B da $\mathrm{CLT}^{9}$ ) que legaliza a contratação do trabalhador como pessoa

\footnotetext{
${ }^{9}$ Art. 442-B da CLT. A contratação do autônomo, cumpridas por este todas as formalidades legais, com ou sem exclusividade, de forma contínua ou não, afasta a qualidade de empregado prevista no art. 3ํㅡㄹ desta Consolidação. (Incluído pela Lei n 13.467, de 2017)

Revista Labor Fortaleza/CE, jul/dez 2018 n 20, Vol. 01, pp. 54-77 ISSN 1983-5000
} 
jurídica em substituição ao contrato assalariado, o que pode configurar uma relação de emprego disfarçada.

Para além das formas atípicas de contratação, a nova legislação trabalhista traz outras modificações, tais como: (1) autoriza as empresas a demitirem trabalhadores sem necessidade de homologação por parte de sindicato ou de autoridade do Ministério do Trabalho; (2) possibilita que a rescisão do contrato seja realizada de comum acordo, em que o trabalhador receberá o metade do aviso prévio (se indenizado) e metade da indenização sobre o saldo do FGTS, somente $80 \%$ dos valores depositados a título de FGTS e não terá direito ao seguro desemprego; e (3 abre a possibilidade de as partes assinarem um termo de quitação anual de obrigações trabalhistas durante a vigência do contrato, em situação em que não há equilíbrio entre o empregador e aquele que está dependendo do emprego para sobreviver.

Em nossa análise, com essas previsões legais supracitadas, se evidencia que há uma certa facilidade para o empregador contratar e demitir seus empregados com uma redução de custos e sem a participação da entidade sindical, o que deixa o trabalhador em uma condição de maior insegurança, vulnerabilidade e risco, com consequências negativas sobre a vida pessoal, familiar e social.

Houve mudanças também no que se refere à duração de trabalho, destacando-se as medidas de ampliação dos mecanismos de compensação das jornadas por meio do banco de horas e a faculdade de se firmar acordos individuais para realização de serviços extraordinários. Além disso, ficou assegurado o fim da obrigatoriedade da empresa comunicar às autoridades competentes caso precise estender a jornada diária por alguma "necessidade imperiosa".

Ainda no que se refere à jornada de trabalho, as novas regras trouxeram um conjunto de novidades que ampliam as estratégias de como valer-se do tempo do trabalhador em prol dos interesses empresariais, tais como: (1) as pausas para amamentação serão objeto de livre negociação com o empregador; (2) o parcelamento de férias em até três períodos, nunca inferior a cinco dias, o que também abre possibilidade de o empregador organizar o período das férias de acordo com as suas necessidades no ano; (3) o tempo de deslocamento para exercício da atividade em locais sem transporte público e de difícil acesso (horas in itinere) deixa de ser considerado como jornada; (4) considerar como jornada somente o tempo efetivamente trabalhado, desconsiderando as atividades, tais como a vestimenta do uniforme, os exercícios, as atividades de comunicação e aviso etc.; (5) abrir a possibilidade de negociar a redução do intervalo de repouso e alimentação para menos de 1 hora; (6) a não previsão de pagamento de horas extraordinárias no caso de home office. 
No que diz respeito, especificamente, à redução do intervalo para repouso durante a jornada (intervalo intrajornada), autorizado pelo art. 611-A da CLT (acrescido pela Lei $n^{\circ}$ 13.467/2017), é de bom alvitre chamar a atenção para a hipótese do mesmo ser inconstitucional, já que afronta o art. $7^{\circ}$, inc. XXII, da Constituição Federal, que estabelece como direito dos trabalhadores urbanos e rurais "a redução dos riscos inerentes ao trabalho, por meio de normas de saúde, higiene e segurança", constituindo inclusive tal dispositivo cláusula pétrea e , portanto, não podendo ser abolidos ou reduzidos nem mesmo por emenda constitucional.

Entretanto, num verdadeiro retrocesso de avanços sociais, o legislador incluiu a hipótese de reduzir o tempo para almoço sem, nem mesmo atentar para os riscos que tal flexibilidade pode trazer para o aumento de acidentes de trabalho e de doenças profissionais, que podem ser ocasionados por maiores ritmo e intensidade de trabalho sem o devido descanso.

As alterações promovidas na legislação também atingiram à questão inerentes à remuneração. Dentre elas, aparece a possibilidade de ocorrer a redução salarial por meio da negociação coletiva ou ainda por meio de pacto individual ${ }^{10}$, caso o empregado tenha uma remuneração superior a dois tetos previdenciários. Também, a incitação ao emprego da remuneração variável, especialmente com o programa de Participação nos Lucros e Resultados, e com a viabilidade do empregador pagar não exclusivamente o salário em pecúnia, mas remunerando o trabalhador com bens, bônus e serviços.

Outra crítica que se faz à Reforma Trabalhista é que ela permite que pactos laborais (convenções e acordos coletivos de trabalho) possam prevalecer sobre a legislação (prevalência

\footnotetext{
${ }^{10}$ Em relação à negociação individual, para além da admissibilidade de redução salarial, a nova lei acrescenta que, para o empregado portador de diploma de nível superior e que perceba salário mensal igual ou superior a 2 vezes o limite máximo do Regime Geral da Previdência Social (RGPS), é permitido a estipulação das relações contratuais de trabalho com a mesma eficácia legal e preponderância sobre os instrumentos coletivos relativamente às matérias cuja negociação coletiva admite (art. 444, parágrafo único, CLT), tais como: I - pacto quanto à jornada de trabalho, observados os limites constitucionais; II - banco de horas anual; III - intervalo intrajornada, respeitado o limite mínimo de trinta minutos para jornadas superiores a seis horas; IV - adesão ao Programa Seguro-Emprego (PSE); V - plano de cargos, salários e funções compatíveis com a condição pessoal do empregado, bem como identificação dos cargos que se enquadram como funções de confiança; VI regulamento empresarial; VII - representante dos trabalhadores no local de trabalho; VIII - teletrabalho, regime de sobreaviso, e trabalho intermitente; IX - remuneração por produtividade, incluídas as gorjetas percebidas pelo empregado, e remuneração por desempenho individual; X - modalidade de registro de jornada de trabalho; XI - troca do dia de feriado; XII - enquadramento do grau de insalubridade; XIII prorrogação de jornada em ambientes insalubres, sem licença prévia das autoridades competentes do Ministério do Trabalho (MTb) ; XIV prêmios de incentivo em bens ou serviços, eventualmente concedidos em programas de incentivo; XV - participação nos lucros ou resultados da empresa (art. 611-A da CL T).
}

Revista Labor Fortaleza/CE, jul/dez 2018 n² 20, Vol. 01, pp. 54-77 ISSN 1983-5000 
do negociado sobre o legislado). Os artigos 611- $\mathrm{A}^{11}$ e 611-B ${ }^{12}$ da CLT, acrescidos pela Lei $\mathrm{n}^{\circ}$ 13.467/2017, apontam, respectivamente, os direitos que podem ser reduzidos ou alterados pela negociação coletiva e os direitos que não podem ser negociados coletivamente, impondo limites a negociação.

A crítica que se faz é que a norma, notoriamente, não teve o objetivo de ampliar direitos, pois isso sempre foi possível. Na verdade, o art. 611-A autoriza a ampla flexibilização,

\footnotetext{
${ }^{11}$ Art. 611-A. A convenção coletiva e o acordo coletivo de trabalho têm prevalência sobre a lei quando, entre outros, dispuserem sobre:

I - pacto quanto à jornada de trabalho, observados os limites constitucionais;

II - banco de horas anual;

III - intervalo intrajornada, respeitado o limite mínimo de trinta minutos para jornadas superiores a seis horas;

IV - adesão ao Programa Seguro-Emprego (PSE), de que trata a Lei n 13.189 , de 19 de novembro de 2015;

V - plano de cargos, salários e funções compatíveis com a condição pessoal do empregado, bem como identificação dos cargos que se enquadram como funções de confiança;

VI - regulamento empresarial;

VII - representante dos trabalhadores no local de trabalho;

VIII - teletrabalho, regime de sobreaviso, e trabalho intermitente;

IX - remuneração por produtividade, incluídas as gorjetas percebidas pelo empregado, e remuneração por desempenho individual;

$\mathrm{X}$ - modalidade de registro de jornada de trabalho;

$\mathrm{XI}$ - troca do dia de feriado;

XII - enquadramento do grau de insalubridade;

XIII - prorrogação de jornada em ambientes insalubres, sem licença prévia das autoridades competentes do Ministério do Trabalho;

XIV - prêmios de incentivo em bens ou serviços, eventualmente concedidos em programas de incentivo;

XV - participação nos lucros ou resultados da empresa.

${ }^{12}$ Art. 611-B. Constituem objeto ilícito de convenção coletiva ou de acordo coletivo de trabalho, exclusivamente, a supressão ou a redução dos seguintes direitos.

I - normas de identificação profissional, inclusive as anotações na Carteira de Trabalho e Previdência Social;

II - seguro-desemprego, em caso de desemprego involuntário;

III - valor dos depósitos mensais e da indenização rescisória do Fundo de Garantia do Tempo de Serviço (FGTS);

IV - salário mínimo;

V - valor nominal do décimo terceiro salário;

VI - remuneração do trabalho noturno superior à do diurno;

VII - proteção do salário na forma da lei, constituindo crime sua retenção dolosa;

VIII - salário-família;

IX - repouso semanal remunerado;

X - remuneração do serviço extraordinário superior, no mínimo, em 50\% (cinquenta por cento) à do normal;

$\mathrm{XI}$ - número de dias de férias devidas ao empregado;

XII - gozo de férias anuais remuneradas com, pelo menos, um terço a mais do que o salário normal;

XIII - licença-maternidade com a duração mínima de cento e vinte dias;

XIV - licença-paternidade nos termos fixados em lei;

$\mathrm{XV}$ - proteção do mercado de trabalho da mulher, mediante incentivos específicos, nos termos da lei;

XVI - aviso prévio proporcional ao tempo de serviço, sendo no mínimo de trinta dias, nos termos da lei;

XVII - normas de saúde, higiene e segurança do trabalho previstas em lei ou em normas regulamentadoras do Ministério do Trabalho;

XVIII - adicional de remuneração para as atividades penosas, insalubres ou perigosas;

XIX - aposentadoria;

$\mathrm{XX}$ - seguro contra acidentes de trabalho, a cargo do empregador;

XXI - ação, quanto aos créditos resultantes das relações de trabalho, com prazo prescricional de cinco anos para os trabalhadores urbanos e rurais, até o limite de dois anos após a extinção do contrato de trabalho;

XXII - proibição de qualquer discriminação no tocante a salário e critérios de admissão do trabalhador com deficiência;

XXIII - proibição de trabalho noturno, perigoso ou insalubre a menores de dezoito anos e de qualquer trabalho a menores de dezesseis anos, salvo na condição de aprendiz, a partir de quatorze anos;

XXIV - medidas de proteção legal de crianças e adolescentes; (Incluído pela Lei n ${ }^{\circ} 13.467$, de 2017)

XXV - igualdade de direitos entre o trabalhador com vínculo empregatício permanente e o trabalhador avulso; (Incluído pela Lei $\mathrm{n}^{\circ} 13.467$, de $\underline{2017)}$

XXVI - liberdade de associação profissional ou sindical do trabalhador, inclusive o direito de não sofrer, sem sua expressa e prévia anuência, qualquer cobrança ou desconto salarial estabelecidos em convenção coletiva ou acordo coletivo de trabalho; (Incluído pela Lei ${ }^{\circ}$ 13.467, de $\underline{2017)}$

XXVII - direito de greve, competindo aos trabalhadores decidir sobre a oportunidade de exercê-lo e sobre os interesses que devam por meio dele defender; (Incluído pela Lei n ${ }^{\circ} 13.467$, de 2017)

XXVIII - definição legal sobre os serviços ou atividades essenciais e disposições legais sobre o atendimento das necessidades inadiáveis da comunidade em caso de greve; (Incluído pela Lei $\mathrm{n}^{\circ} 13.467$, de 2017)

XXIX - tributos e outros créditos de terceiros; (Incluído pela Lei ${ }^{\circ} 13.467$, de 2017)

XXX - as disposições previstas nos arts. 373-A, 390, 392, 392-A, 394, 394-A, 395, 396 e 400 desta Consolidação.

Revista Labor Fortaleza/CE, jul/dez 2018 n 20, Vol. 01, pp. 54-77 ISSN $1983-5000$
} 
aumentando o leque de possibilidades de direitos previstos em lei que podem reduzidos ou suprimidos. (CASSAR, 2018).

Observe-se que o caput do art. 611-A da CLT coloca em outras palavras que os direitos elencados nos incisos são meramente exemplificativos, portanto, podendo esse rol ser ampliado. À vista disso, depreende-se que a prevalência do negociado sobre o legislado enfraquece o princípio da indisponibilidade dos direitos trabalhistas, transformando-os em direitos disponíveis e de características puramente de direito privado.

Não obstante o presente diagnóstico não abordar todos os dispositivos legais incluídos pela Reforma Trabalhista, o que aqui foi analisado já é suficiente para demonstrar os enormes riscos que essa mudança de paradigma - já vigentes, e com importantes impactos já nos próximos anos - poderá significar para o mundo do trabalho e para a situação social de milhões de assalariados.

\section{CONSIDERAÇÕES FINAIS}

Num contexto de grande inovação tecnológica, o mundo do trabalho passa por profundas modificações e torna-se, cada vez mais, digital e flexível, o que para alguns pode ser a oportunidade de superar as desigualdades, economizar de horas de trabalho, promover a vida digna, melhorar as condições de trabalho, ampliar a proteção social e repartir melhor os ganhos de produtividade.

Contudo, a lógica do capital não é essa. Numa economia monetária da produção, o processo de concorrência exige dos empresários não apenas manter a empresa, mas os obriga, simultaneamente, à busca permanente da superação das normas de produção existentes, das mudanças organizacionais, Estas últimas dizem respeito particularmente às inovações nas relações de trabalho - hierarquias empresariais e processos motivacionais - na procura incessante de padrões de gestão mais ajustados ao objetivo de suplantar os padrões estabelecidos (BELLUZZO, 2012).

Dentro dessa dinâmica e acompanhando uma tendência mundial, em 2017, o Brasil promoveu a Reforma Trabalhista por meio das leis 13.467 e 13.429 , cujas principais características foram restrição aos direitos dos trabalhadores e ampliação da liberdade das empresas na administração do trabalho de acordo com os seus interesses, de modo que as alterações pudessem reduzir o custo das empresas e ampliar a sua liberdade em determinar as condições de contratação, uso e remuneração da força de trabalho, bem como a tentativa de enfraquecimento das instituições públicas relacionadas ao trabalho (Justiça do Trabalho, 
Ministério Público do Trabalho e Ministério do Trabalho), como estratégia de redefinição do papel do Estado

Nessas circunstâncias se percebe, entre as muitas propensões, que haverá um avanço das terceirizações e das novas modalidades de contratações, como o uso do trabalho intermitente e teletrabalho, concorrendo cada vez mais para precarização estrutural, submetendo o trabalhador a mais insegurança, na medida em que amplia a liberdade do empregador em determinar as condições de contratação, o uso da mão de obra e a remuneração do trabalho e, com efeito, redução da proteção social aos assalariados.

Esse cenário parece muito desfavorável, mas, apesar disso, não é inalterável. Depreende-se que o embate em torno da regulação do trabalho continuará e o que o resultado dessa disputa, nos próximos anos, dependerá da resistência da classe trabalhadora, de seus representantes sindicais.

Outrossim, a Reforma Trabalhista, por enquanto, é uma prescrição dentro do ordenamento jurídico pátrio que - a despeito das mudanças estabelecidas à Justiça do Trabalho - ainda depende de uma hermenêutica jurídica e posterior aplicação pelas demais instituições e agentes públicos que o fazem de modo relativamente crítico e, provavelmente, levarão em conta os aspectos epistemológicos que deram origem ao direito do Trabalho, ou seja, priorizar o bem-estar social dos trabalhadores.

\section{REFERÊNCIAS BIBLIOGRÁFICAS}

ANTUNES, Ricardo. A desertificação neoliberal no Brasil (Collor, FHC e Lula). Campinas: Autores Associados, 2004.

ANTUNES, Ricardo. O privilégio da servidão: o novo proletariado de serviços na era digital. São Paulo: Boitempo, 2018.

BARDIN, L. Análise de conteúdo. São Paulo: 70, 2011.

BELLUZZO. O capital e suas metamorfoses. São Paulo: Ed. UNESP, 2012.

BRASIL. Decreto-Lei n ${ }^{\circ} 5.452$, de $1^{\circ}$ de maio de 1943. Aprova a Consolidação das Leis do Trabalho. Diário Oficial a União, Brasília, DF, 9 ago. 1943.

BRASIL. Câmara dos Deputados Federais. Projeto de Lei $\mathbf{n}^{\mathbf{0}}$ 4330, de 26 de outubro de 2004. Dispõe sobre o contrato de prestação de serviço a terceiros e as relações de trabalho dele decorrentes. Disponível em:

https://www.camara.gov.br/proposicoesWeb/fichadetramitacao?idProposicao=267841.

Acesso em: 20 set. 2018. 
BRASIL. Lei $\mathrm{n}^{\circ} 11.648$, de 31 de março de 2008. Dispõe sobre o reconhecimento formal das centrais sindicais para os fins que especifica, altera a Consolidação das Leis do Trabalho CLT, aprovada pelo Decreto-Lei $n^{\circ} 5.452$, de $1^{\circ}$ de maio de 1943, e dá outras providências. Diário Oficial a União, Brasília, DF, 31 mar. 2008.

BRASIL. Medida Provisória $n^{\circ}$ 665, de 30 de dezembro de 2014. Altera a Lei $\mathrm{n}^{\circ}$ 7.998, de 11 de janeiro de 1990, que regula o Programa do Seguro-Desemprego, o Abono Salarial e institui o Fundo de Amparo ao Trabalhador - FAT, altera a Lei ${ }^{\circ} 10.779$, de 25 de novembro de 2003, que dispõe sobre o seguro desemprego para o pescador artesanal, e dá outras providências. Presidência da República. Diário Oficial da União, Brasília, DF, 30 dez. 2014.

BRASIL. Lei $\mathrm{n}^{\circ} 13.134$, de 16 de junho de 2015. Altera as Leis $\mathrm{n}^{\circ} 7.998$, de 11 de janeiro de 1990, que regula o Programa do Seguro-Desemprego e o Abono Salarial e institui o Fundo de Amparo ao Trabalhador (FAT), $\mathrm{n}^{\circ} 10.779$, de 25 de novembro de 2003, que dispõe sobre o seguro-desemprego para o pescador artesanal, e $\mathrm{n}^{\circ}$ 8.213, de 24 de julho de 1991, que dispõe sobre os planos de benefícios da Previdência Social; revoga dispositivos da Lei $\mathrm{n}^{\circ}$ 7.998, de 11 de janeiro de 1990, e as Leis $n^{0} 7.859$, de 25 de outubro de 1989, e no 8.900, de 30 de junho de 1994; e dá outras providências. Diário Oficial da União, Brasília, DF, 17 jun. 2015.

BRASIL. Lei no 13.429, de 31 de março de 2017. Altera dispositivos da Lei no 6.019 , de 3 de janeiro de 1974, que dispõe sobre o trabalho temporário nas empresas urbanas e dá outras providências; e dispõe sobre as relações de trabalho na empresa de prestação de serviços a terceiros. Diário Oficial da União, Brasília, DF, 31 mar. 2017.

BRASIL. Lei n ${ }^{\circ}$ 13.467, de 13 de julho de 2017. Altera a Consolidação das Leis do Trabalho (CLT), aprovada pelo Decreto-Lei $\mathrm{n}^{\mathrm{o}}$ 5.452, de $1^{\mathrm{o}}$ de maio de 1943 , e as Leis $\mathrm{n}^{\mathrm{os}} 6.019$, de 3 de janeiro de 1974, 8.036, de 11 de maio de 1990, e 8.212, de 24 de julho de 1991, a fim de adequar a legislação às novas relações de trabalho. Diário Oficial da União, Brasília, DF, 14 jul. 2017.

BRASIL. Decreto n 9.507 , de 21 de setembro de 2018. Dispõe sobre a execução indireta, mediante contratação, de serviços da administração pública federal direta, autárquica e fundacional e das empresas públicas e das sociedades de economia mista controladas pela União.. Diário Oficial a União, Brasília, DF, 24 set. 2018.

CASSAR, Vólia Bonfim. Direito do Trabalho: de acordo com a reforma trabalhista Lei 13.467/2017. $15^{\text {a }}$ ed. Rio de Janeiro: Forense; São Paulo: MÉTODO, 2018.

DELGADO, Maurício Godinho. Curso de Direito do Trabalho. 3. Ed. São Paulo: LTr, 2004.

IANNI, Octavio. A era do globalismo. Rio de Janeiro: Civilização Brasileira, 1996.

KREIN, José Dari. O desmonte dos direitos, as novas configurações do trabalho e o esvaziamento da ação coletiva: consequências da reforma trabalhista. Tempo soc., Abr 2018, vol.30, no.1, p.77-104. ISSN 0103-2070. Disponível em:

http://www.scielo.br/pdf/ts/v30n1/1809-4554-ts-30-01-0077.pdf. Acesso em: 01/10/2018.

LOCKE, John. Segundo Tratado Sobre o Governo Civil e Outros Escritos. Tradução Magda Lopes e Marisa Lobo da Costa. Petrópolis, RJ: Vozes, 1994..

Revista Labor Fortaleza/CE, jul/dez 2018 n² 20, Vol. 01, pp. 54-77 ISSN 1983-5000 
MARTINS, H.S.; RODRIGUES, I. J. O sindicalismo brasileiro na segunda metade dos anos 90. Tempo Social: 11 (2), 1999.

MARX. Karl. Manuscritos econômicos-filosóficos. Tradução Jesus Raniere. São Paulo, Boitempo, 2004.

PMDB. (2015), “Uma ponte para o futuro”. Disponível em https://www.fundacaoulysses.org.br/wp-content/uploads/2016/11/UMA-PONTE-PARA-OFUTURO.pdf-Online.pdf, consultado em 20/9/2018. 